\title{
Phytoprotection
}

\section{Use of Fungi for Pest Control in Sustainable Agriculture}

\section{Siegfried Keller}

Volume 79, numéro 4, 1998

OECD Workshop - Sustainable Pest Management, Safe Utilization of New Organisms in Biological Control. Montréal, Québec, Canada. September 27-30, 1998.

Atelier de l'OCDE - Gestion durable des ennemis des cultures,

Utilisation sécuritaire de nouveaux organismes de lutte biologique. Montréal, Québec, Canada. 27-30 Septembre 1998.

URI : https://id.erudit.org/iderudit/706158ar

DOI : https://doi.org/10.7202/706158ar

Aller au sommaire du numéro

Éditeur(s)

Société de protection des plantes du Québec (SPPQ)l

ISSN

0031-9511 (imprimé)

1710-1603 (numérique)

Découvrir la revue

Citer cet article

Keller, S. (1998). Use of Fungi for Pest Control in Sustainable Agriculture.

Phytoprotection, 79(4), 56-60. https://doi.org/10.7202/706158ar

\section{Résumé de l'article}

The registration procedures for microbial pesticides have been based by and large on those developed for registration of chemical pesticides. However, fungi as living organisms differ in many aspects from inert substances. These differences are pointed out and discussed in the light of practical experiences. A pragmatic registration procedure is proposed taking into account the use of a fungus based product in relation to its natural distribution and behaviour. On the one hand, the use of a fungus naturally occurring on the target host does not need a sophisticated registration procedure. On the other hand, however, a genetically altered fungus applied against a non natural host in a non natural habitat needs very careful examination.
Ce document est protégé par la loi sur le droit d'auteur. L'utilisation des services d’Érudit (y compris la reproduction) est assujettie à sa politique d'utilisation que vous pouvez consulter en ligne.

https://apropos.erudit.org/fr/usagers/politique-dutilisation/ 


\title{
Use of Fungi for Pest Control in Sustainable Agriculture
}

\author{
Siegfried Keller
}

Swiss Federal Research Station for Agroecology and Agriculture, Reckenholz, CH-8046 Zurich

\begin{abstract}
The registration procedures for microbial pesticides have been based by and large on those developed for registration of chemical pesticides. However, fungi as living organisms differ in many aspects from inert substances. These differences are pointed out and discussed in the light of practical experiences. A pragmatic registration procedure is proposed taking into account the use of a fungus based product in relation to its natural distribution and behaviour. On the one hand, the use of a fungus naturally occurring on the target host does not need a sophisticated registration procedure. On the other hand, however, a genetically altered fungus applied against a non natural host in a non natural habitat needs very careful examination.
\end{abstract}

\section{INTRODUCTION}

Several hundred species of fungi are known to infect and kill insects and mites. The most important groups are the Hyphomycetes within genera like Beauveria, Metarhizium, Verticillium, Paecilomyces and Hirsutella, the Ascomycetes within the genus Cordyceps and the Entomophthorales with a total of 12 genera and some 230 insect and mite pathogenic species. The latter is nearly unexploited although $30 \%$ of these attack pest species or vectors of diseases of humans and domestic animals. This diversity bears an enormous potential for pest and vector control. In the future, therefore, and especially in the context of the efforts to favour sustainable agriculture, we can expect a considerable increase in the use of fungi for pest control.

The preferred environment for Hyphomycetes and Cordyceps is the soil whereas nearly all Entomophthorales are found above the soil level. Most species are specific pathogens and attack single host species or a limited number of related host species. The entomopathogenic soil fungi are characterised by small conidia, relatively low virulence (i.e. a large number of conidia is needed to infect and kill the host), a relatively long incubation time and a slow self propagation. In contrast, the Entomophthorales have large structures and resting spores, a single conidium or few conidia can infect and kill the host, death occurs within a few days and the self propagation is fast. These characteristics must be considered as an adaptation to the environment and have implications for their use as microbial control agents.

\section{USE OF FUNGI FOR PEST CONTROL}

Fungi are important enemies of many pest species and are able to control pest populations naturally. There are two fundamentally different ways to use fungi for pest control: 
1. Favouring those being present naturally by manipulation of the environment (e.g. habitat management). This will not be discussed here although it is an important strategy for sustainable agriculture.

2. In vitro or in vivo production and application. The fungus can be introduced into the host population with a single application using technical equipment or autodissemination techniques, or it can be applied repeatedly like a chemical. The aim of the application is to achieve shortterm or long-term control, to enhance epizootics and/or to establish the pathogen in the host population.

There are several examples in the literature demonstrating the successful use of these techniques for pest control like the introduction and release of Entomophaga maimaiga resulting in epizootics and long-term control of the gypsy moth in north-eastern USA, the treatment of adult cockchafer with Beauveria brongniartii using the females as vectors of the disease to contaminate the breeding sites resulting in long-term control in north-eastern Switzerland or the repeated treatment of spittle-bugs with Metarhizium anisopliae in Brazil. Other techniques applied to entomopathogenic fungi like transgenic or genetically altered strains or their use as endophytes are not discussed here.

\section{FUNGI ARE DIFFERENT FROM CHEMICALS}

\section{Life cycle}

Fungi are organisms, living beings. They infect their hosts with spores (conidia) which germinate on the epidermis. The germ tubes penetrate the skin and enter the body cavity where multiplication starts. The fungi develop vegetatively as protoplasts, hyphal bodies, hyphae or yeast-like structures called blastospores. Most tissues become invaded. Some fungi produce metabolites which are toxic to the host or competing microorganims. At the end of the parasitic stage the host dies and its body is filled with fungal material, either mycelium, hyphal bodies or resting stages.

Under favourable conditions the fungus switches to the saprophytic phase. Hyphae or conidiophores emerge from their host by penetrating the host cuticle from within the cadaver. The Entomophthorales form a single layer of conidia on the host surface, whereas the Hyphomycetes form a more or less conspicuous mycelial mat around the host which produces the conidia, the structures responsible for dissemination and infection of new hosts.

\section{Factors related to the organismic character}

Genetic diversity: Any fungal species possesses a genetic diversity which can be used to subdivide it into strains. These strains can show different reactions to abiotic factors such as environmental conditions, nutrients or chemicals including pesticides, or to biotic factors such as virulence or persistence.

Host range/specificity: Under natural conditions most species have a limited host range. But species with a wide host range also tend to be more virulent for the host from which they were originally isolated. They can be classified into pathotypes based on their specificity.

Self-propagation: A limited number of fungal spores are able to start a multiplication process, which results in a thousand to billion fold increase of the spore amount. This can also happen at the population level as a result of an outbreak or the induction of an epizootic which can result in remarkable aerial spore densities.

Dissemination: With the ability to project conidia or to grow saprophytically the entomopathogenic fungi have a limited possibility to actively disseminate. The most important way of dissemination occurs passively via infected hosts, other individuals or transportation of spores in the wind.

Metabolites: Metabolites are mainly known from Hyphomycetes. Than can be toxic for the host and reduce the incubation time or they can help the fungus to compete with other microorganisms. 


\section{WHITE GRUB CONTROL WITH BEAUVERIA BRONGNIARTII WITH REGARD TO REGISTRATION}

\section{The European cockchafer Melolontha} melolontha L. (Coleoptera, Scarabaeidae) is a serious pest in many regions of central Europe. A generation lasts three years. It develops synchronously in outbreak areas resulting in flights every three years. During the flight period the adults concentrate at the borders of forests for about two weeks. After the feeding/egg maturation period the females fly back to their breeding sites and deposit the eggs in the soil. The larvae feed on roots of nearly all cultivated plants, but most damage is done in grassland. Since the ban of the organochlorines there are no longer any registered insecticides for control of this pest. That is why we started a programme to control the white grubs with the hyphomycete Beauveria brongniartii (Sacc.) Petch.

As a first approach we produced blastospores and treated the swarming adults with the aim to use the females to carry the pathogen into the soil of the breeding sites. Two large field trials were done in 1985 and in 1988. For each trial we treated about 100 ha of forest borders. Secondary effects on honey bees, birds, insect and spiders living in the same enviroment were studied. Good control of the pest was achieved after two generations. In a second approach we developed a product which could be applied by farmers. This product is based on fungus colonised cereal grains ("fungus kernels") and has been registered since 1990 and is presently being produced by two companies.

At the beginning of the field experiments there was no specific protocol for the registration of microbial control agents. In close collaboration between the registration officials, external specialists and scientists involved in the trials, a registration procedure was developed which can be considered as a good compromise between theoretical and practical claims. Experiences from this process as well as general remarks are presented in the following sections.

\section{STEPS IN THE DEVELOPMENT OF A MYCOINSECTICIDE}

Strains with the desired characteristics must be selected before production can start. Desired characteristics are mainly virulence for given hosts, production criteria (nutrients, time) and specificity, especially absence of adverse effects on vertebrates and plants. Additional characteristics can include metabolites, resistance to environmental conditions or longevity. Production can take place in liquid cultures, on solid media or using a combination of both. Production must be seen in relation to the final product and its application. For aerial application a liquid product may be best, while a granule may be best for a soil treatment. Production parameters can be chosen to produce blastospores, conidia or fungal aggregates. Furthermore, they can be used to avoid or suppress production of undesired metabolites. Additives are used to improve or to stabilize the product. These are used for example as wetting or sticking agents, as humefactants and UV protectants or as host attractants. Any additive should not have adverse effects on organisms.

The production and formulation process should be followed by a quality control including purity of the product (foreign microoganisms, undesired metabolites) and virulence. A check of the genetic identity before and after the process gives information on the stability of the fungus.

The application must be done carefully and directed against the target. The use of a fungus against its natural host in the natural environment bears little risk, while its application against non-natural hosts in non-natural environments is problematic (fig. 1) and increases the possibilities of undesired secondary effects. A careful monitoring of the trials helps to understand the ecology of the applied fungus and the interactions with the environment. 


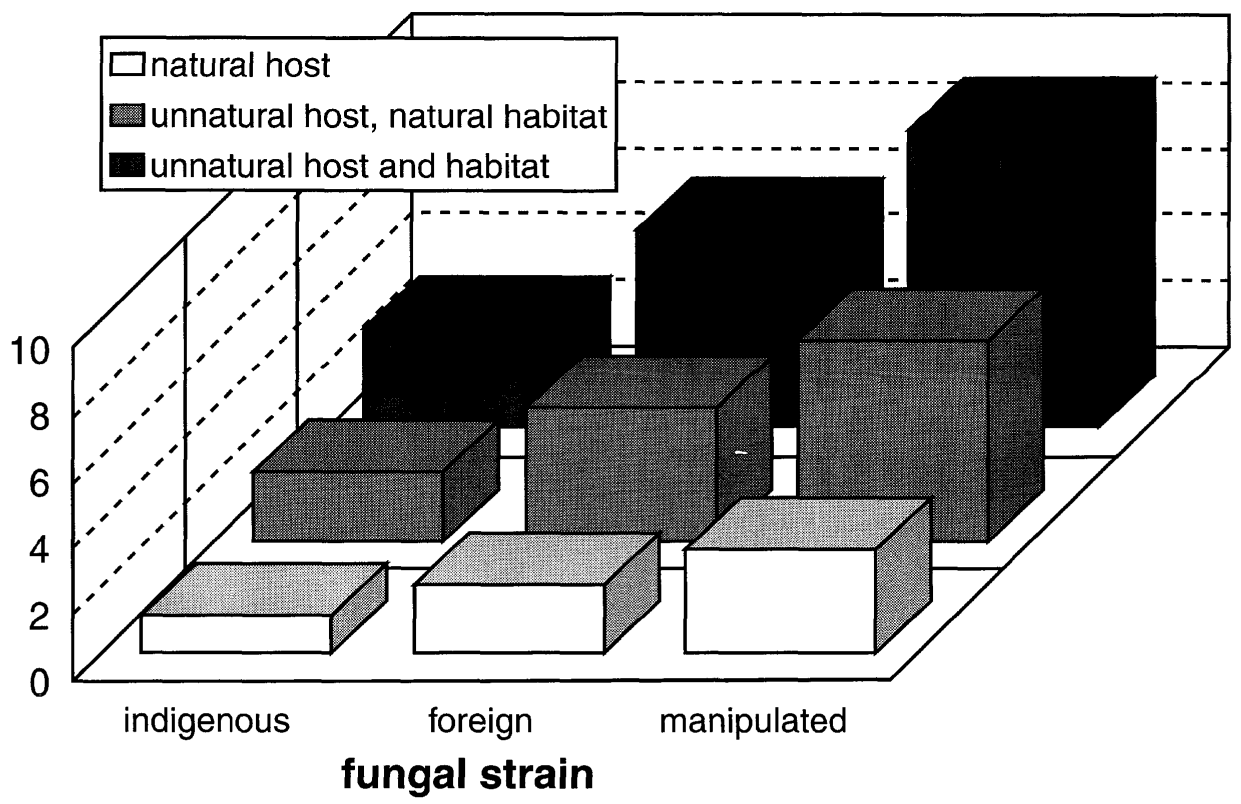

Fig. 1: The needs for the registration of fungal products, indicated by the height of the columns, should be based mainly on the fungal strain and the environment, in which the product is applied.

\section{CRITICAL DOMAINS IN RESPECT TO REGISTRATION}

\begin{tabular}{ll}
\hline Domain & Characters \\
\hline Fungal species & $\begin{array}{l}\text { Biology, host range, natural distribution, observations from nature, } \\
\text { data from literature }\end{array}$ \\
Strain & $\begin{array}{l}\text { Origin (locality, host), virulence, wild strain or genetically altered, } \\
\text { genetical characterisation and markers } \\
\text { Metabolites }\end{array}$ \\
$\begin{array}{l}\text { Natural and induced metabolites, importance, presence/ absence in } \\
\text { product } \\
\text { Secondary effects }\end{array}$ & $\begin{array}{l}\text { Reactions of humans, other vertebrates and other non-targets, host } \\
\text { range, pathogenicity for honey bees and selected beneficials }\end{array}$ \\
\hline
\end{tabular}

\section{NEEDS FOR SAFE EXPLOITATION}

Entomopathogenic fungi have evolved with the insects hundreds of millions of years ago and are still evolving. They are part of our natural environment and have interacted with humans as long as they existed. A lot of knowledge on these interactions has accumulated in the last centennarium allowing us to separate critical from non-critical species. Nevertheless there are enough reasons to subject them to a registration procedure. This, however, should be a pragmatic one based on the two principles (fig. 1):

1. The registration procedure should be viewed with regard to the situation under which a fungal product is used. 
2. The closer the use is to the natural situation, the less requirements are needed and vice-versa.

A few examples are given to illustrate these principles: A fungus is known to produce toxins, but it doesn't make sense to consider these if they are not present in the final product. If a product is applied to the soil, side effects on non hypogeaic organisms should not be tested. A product based on a soil fungus applied to the soil has to fulfill less requirements than the same product applied in an aerial environment. More examples could be added to demonstrate that the registration procedure should not be too rigid but be adaptable to different situations on a case by case basis.

A two step registration procedure is proposed consisting of a provisional and a full registration. A provisional registration could be given for low risk use (e.g. fungi applied against their natural host in their natural environment). The same but with close limitations ("experimental permit") could be given for higher risk use (e.g. native fungi applied against non-natural hosts in nonnatural environments). Genetically altered fungi could get a provisional registration only after careful examination under quarantine conditions. The advantages of a provisional registration are the following: It is limited in time, it allows use of the fungus to study its ecology and side effects under practical conditions and to answer open questions. It can be withdrawn as soon as undesired effects are observed. A full registration would only be given once the required data were presented, examined and approved. In any case, close collaboration between involved researchers, external experts and registration officials is proposed.

\section{ACKNOWLEDGEMENTS}

The author is greatly indebted to Mark Goettel for reviewing the manuscript and correcting the English phraseology.

\section{QUESTIONS}

1. Entomopathogenic fungi bear an enormous potential for biocontrol. Which measures can be taken to strengthen research on and use of mycoinsecticides?

2. Should fungi be registered as any other entomopathogen, or should they be registered according to a particular protocol?

3. Should transgenic fungal mycoinsecticides be banned? 